NASA Technical Memorandum 101959

\title{
Design, Development, and Applications of Novel Techniques for Studying Surface Mechanical Properties
}

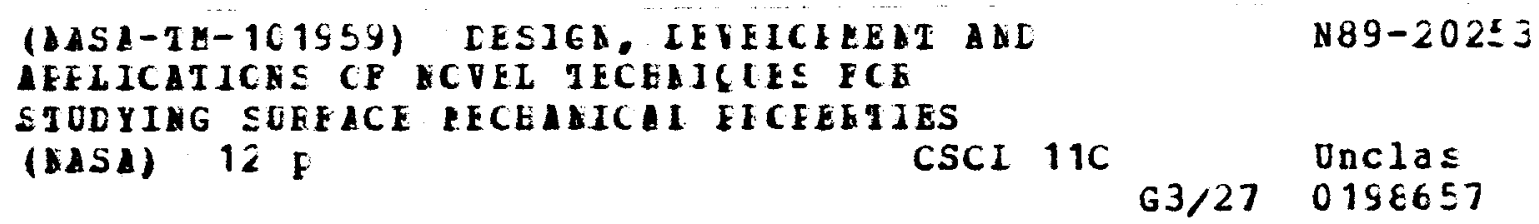

Kazuhisa Miyoshi

Lewis Research Center

Cleveland, Ohio

Prepared for the

Spring Meeting of the Materials Research Society

San Diego, California, April 24-28, 1989 
DESIGN, DEVELOPMENT, AND APPLICATIONS OF NOVEL TECHNIQUES

FOR STUDYING SURFACE MECHANICAL PROPERTIES

KAZUHISA MIYOSHI*

*NASA Lewis Research Center, Cleveland, OH 44135

ABSTRACT

This paper reviews the author's research of the adhesion, friction, and micromechanical properties of materials and presents examples of the results. The ceramic and metallic materials studied include silicon carbide, aluminum oxide, and iron-base amorphous alloys. The design and operation of a torsion balance adapted for study of adhesion from the Cavendish balance are discussed first. The pull-off force (adhesion) and shear force (friction) required to break the interfacial junctions between contacting surfaces of the materials were examined at various temperatures in a vacuum. The surface chemistry of the materials was analyzed by $x$-ray photoelectron spectroscopy. Properties and environmental conditions of the surface regions which affect adhesion and friction - such as surface segregation, composition, crystal structure, surface chemistry, and temperature were also studied.

\section{INTRODUCTION}

Adhesion is an integral part of diverse technologies, such as those involved with friction and wear, crack formation in ceramics, the structural performance of ceramic composite materials and ceramic coatings, and the integrity and packaging of thin-film devices like integrated circuits. Despite the widespread character of adhesion phenomena, the detailed mechanisms of the basic adhesion of ceramic materials are not well understood and are, for the most part, unknown [1-7]. A number of the surface and bulk properties of ceramics affect the nature and magnitude of the interfacial bond forces that develop between these materials. Surface properties include electronic surface states, ionic species present at the surface, chemical structure of the contacting materials, and the presence or absence of surface contaminants. Bulk properties include crystallography. cohesive or lattice energies, ductility or brittleness, and the presence or absence of defects [2-7]. Basic questions remain unanswered: Where does an interface fail, and how does this depend on the chemical structure. mechanical behavior, and stress levels within the interface? How does the adhesive force depend on the interfacial separation? The adhesive properties of ceramics have been studied, but more fundamental research is needed on the nature of adhesive forces and the modes of junction rupture [8].

When two solids are brought into contact and adhesion occurs, there are a variety of methods which can be employed to quantify the bonding forces. Some involve tensile pulling on the interface. The strength of adhesion is usually expressed as the force needed to pull the surfaces apart: that is, the pull-off force [8]. Other methods, such as friction force measurements, are based on tangential shearing of the junction $[1,2]$.

First this paper reviews the newly developed torsional balance adapted for pull-off force measurements from the Cavendish balance and second compares the results obtained by the two methods of quantifying the bonding force (i.e., pull-off force and friction force measurements). Silicon carbide, aluminum oxide, and iron-base amorphous alloys are examined as examples. The silicon carbide is examined in contact with itself at temperatures from room temperature to $900{ }^{\circ} \mathrm{C}$ in vacuum. The aluminum oxide is studied in contact with the iron-base amorphous alloys at temperatures from room temperature to $700^{\circ} \mathrm{C}$ in vacuum. Surface characterization is used to establish surface states and the influence of surface chemistry. 


\section{ADHESION AND FRICTION DEVICE}

\section{ORIGINAL PAGE IS \\ OF POOR QUALITY}

The adhesion and friction devices used in this study were mounted in an ultrahigh vacuum system ( $F i g$. 1) that contained an $x$-ray photoelectron spectroscopy (XPS) spectrometer. The mechanism for measuring adhesion and friction was basically a pin on a flat configuration, as shown schematically in Fig. 1 .

\section{Pull-off Force}

The adhesion measuring device used in this study was a torsion balance adapted from the principle of the Cavendish balance used to measure gravitational forces in 1798 [9]. The adapted torsion balance consists of a solid, A, and a displacement sensor, such as an electromechanical transducer, mounted at opposite ends of a horizontal arm which is supported at its center by a vertical wire, such as a single-strand music wire (Fig. 2 ). Another solid, B, is moved horizontally toward $A$, presses against it, and twists the wire through a small angle with a normal force, the normal loading process, thereby moving the sensor. The solid B is then gradually moved horizontally backward until the two solids are pulled apart in a normal direction, the unloading process. If the force of adhesion between the two solids is zero, A separates from $B$ at its original position and untwists the wire, thereby moving the sensor back to its original position. If an adhesive force between the two solids is present, the force twists

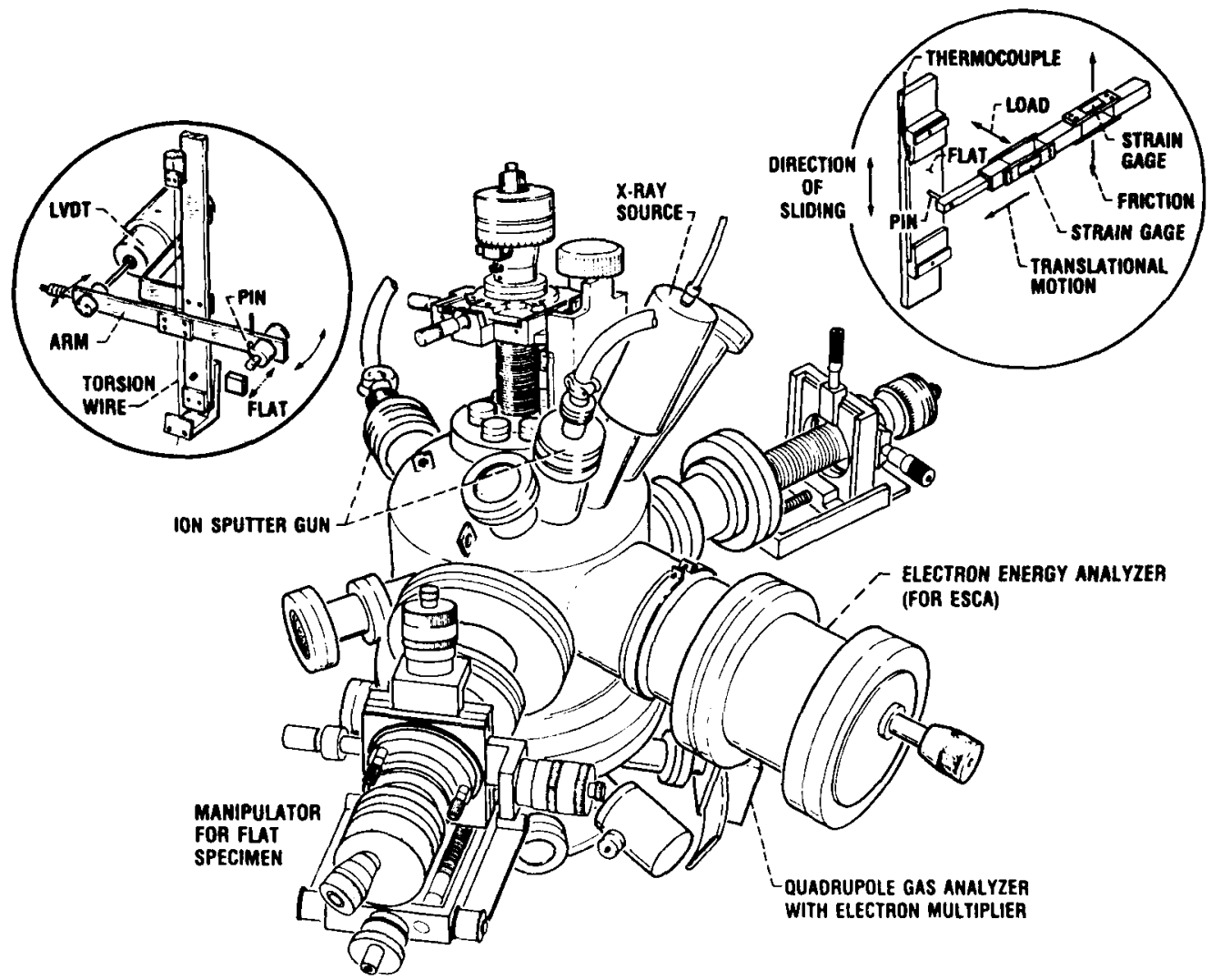

Figure 1. - Apparatus for measuring adhesion and friction in ultrahigh vacuum. 
the wire as $B$ moves backward until the wire develops sufficient force to separate the surfaces of $A$ and $B$ in the normal direction.

In this system, the attractive force of adhesion and the force required to pull the surfaces of two solids apart (the pull-off force) act along a horizontal direction and are not affected by gravity and buoyancy. The axis of weight and buoyancy of all the components (such as the arm, sensor, and wire) is different from that of the pull-off microforce to be measured and is in the vertical direction because of gravity. Therefore, the size and weight of specimens have almost no effect on the accuracy of measuring pulloff forces.

Since the pull-off force is measured by the torsional moment acting on the torsion wire, the force can be calibrated in three ways: (1) by calculation from the geometric shape of the torsion wire such as its length and area of section. (2) by calculation with measured values of natural periods of harmonic motions of the arm when the arm is freely oscillated, and ( 3 ) by direct comparison of microforce to standard weight when the arm and torsion wire are held horizontally. The values of pull-off force determined by all three methods of calibration were nearly the same [10].

For the actual balance shown in Fig. 1, the pin specimen (corresponding to the solid $A$ in Fig. 2) was mounted on one end of a movable arm. $A$ free-moving, rod-shaped magnetic core was mounted on the other end of the arm. The coils of a linear variable differential transformer (LVDT) were mounted on a stationary arm. There was no physical contact between the movable magnetic core and the coil structure. The movable arm was supported by a single strand of music wire acting as a torsion spring. The flat specimen (corresponding to the solid $B$ in Fig. 2) was mounted on a specimen holder attached to a manipulator, which allows electron beam specimen heating in a vacuum.

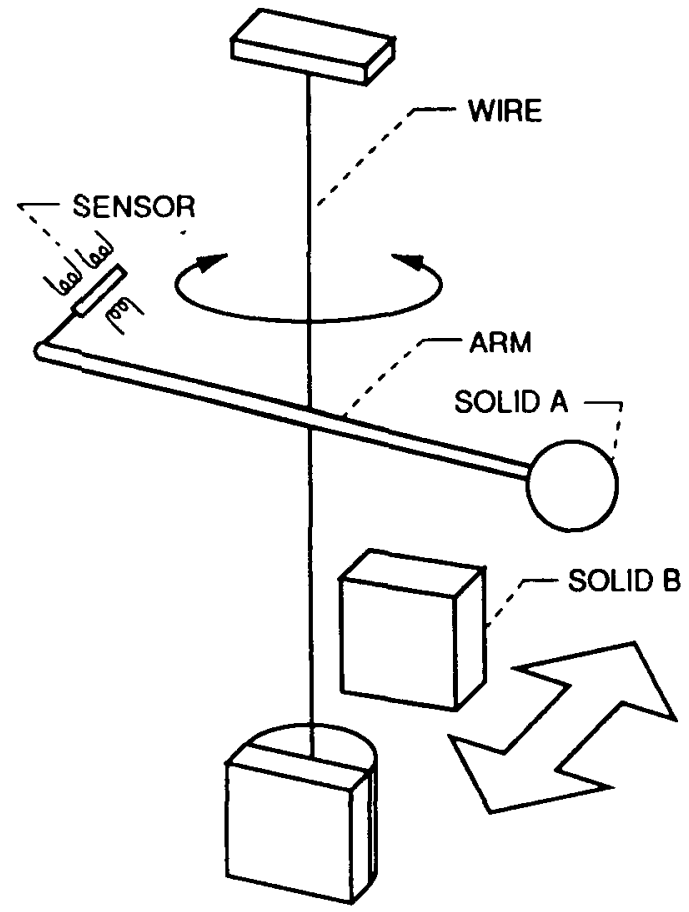

Figure 2. - Schematic diagram of torsion balance adapted from Cavendish balance. 


\section{Friction Force}

Strain gages were used to measure loads and friction forces (Fig. 1). A manipulator-mounted beam was projected into the vacuum system. The beam contained two pairs of flats assembled normal to each other with strain gages mounted thereon. In each pair, the flats were parallel to each other. The end of the beam contained the pin specimen. As the flat specimen mounted on the other manipulator (the same flat specimen used in the adhesion experiments) was moved toward the pin specimen, a load was applied. The load was measured by strain gages mounted on the pair of flats (Fig. 1). Under an applied load, the friction force was measured during vertical translation by strain gages mounted normal to those measuring load. The flat specimen was slid vertically by moving the micrometer-head-screw of the manipulator.

EXPERIMENTAL PROCEDURES

Materials

Silicon carbide. - The single-crystal $\alpha$-SiC flat platelets were a 99.9 percent pure compound of silicon and carbon. The basal plane was parallel to the interface.

The sintered polycrystalline $\alpha-S i C$ used in the experiments was a 98.5 to 98.7 percent pure compound of silicon and carbon. The radius of the sintered polycrystalline pin specimen was $1.6 \mathrm{~mm}$.

Aluminum oxide. - The spherical riders that were made to slide on the amorphous alloys were single-crystal aluminum oxide (sapphire) spheres, $3.2 \mathrm{~mm}$ in diameter.

Amorphous alloys. - Three amorphous alloy (67Fe-18Co-14B-1Si, $81 \mathrm{Fe}-13.5 \mathrm{~B}-3.5 \mathrm{Si}-2 \mathrm{C}, 40 \mathrm{Fe}-38 \mathrm{Ni}-4 \mathrm{Mo}-18 \mathrm{~B}$ ) were examined in this investigation. The alloys were foils, 30 to $33 \mu \mathrm{m}$ thick and were used in the as-cast conditions.

\section{Procedures}

For SiC-to-SiC contact, the contacting surfaces of the pin and flat specimens were polished with diamond powder 1 um in diameter and then with aluminum oxide powder $1 \mu \mathrm{m}$ in diameter. All the specimens in this investigation were rinsed with high-purity ethanol before the experiments. The flat specimen was mounted on a specimen holder with an electron beam heater assembled in a manipulator. The electron beam heater could raise the temperature of the flat specimen to $1200^{\circ} \mathrm{C}$. The temperature was measured with a type $\mathrm{K}(\mathrm{Ni}-\mathrm{Cr} / \mathrm{Ni}-\mathrm{Al})$ thermocouple in contact with the flat specimen. The pin and flat specimens were placed in a vacuum chamber, and the system was evacuated and baked out to achieve a pressure of $30 \mathrm{nPa}$. Then the hemispherical, sintered polycrystalline silicon carbide pin specimens were ionsputter etched with a $3000-\mathrm{eV}$ beam at 25-mA current with an argon pressure of $0.7 \mathrm{mPa}$. The ion beam was continuously rastered over the specimen surface. After sputter etching, the system was reevacuated to a pressure of $30 \mathrm{nPa}$ or lower. Then in situ pull-off force (adhesion) and friction force measurements were conducted with the ion-sputter-cleaned hemispherical sintered polycrystalline silicon carbide pin specimens in contact with the as-received and electron-beam-heated single-crystal silicon carbide flat specimens in ultrahigh vacuum.

For $\mathrm{Al}_{2} \mathrm{O}_{3}$-to-amorphous alloy contact, the pin and flat specimens were rinsed with high-purity ethanol before they were placed in the vacuum chamber. After the specimens had been placed in the vacuum chamber, the system was evacuated and baked out to achieve a pressure of $30 \mathrm{nPa}$. Then, both flat and pin specimens were argon ion sputter cleaned with a $3000-\mathrm{eV}$ beam 
at $25 \mathrm{~mA}$ current with an argon pressure of $0.7 \mathrm{mPa}$. Finally, in situ friction experiments were conducted with the ion-sputter-cleaned aluminum oxide pin in contact with the ion-sputter-cleaned and resistance-heated amorphous alloy flat specimens in ultrahigh vacuum $[11,12]$.

Both flat and pin specimens were analyzed by x-ray photoelectron spectroscopy. The procedures of the XPS analysis are described in detail in references 11 and 12 .

For in situ pull-off force (adhesion) measurements in vacuum, the flat specimen was brought into contact with the pin specimen by moving the micrometer headscrew forward manually. Contact was maintained for $30 \mathrm{sec}$; then the pin and flat specimen surfaces were pulled apart by moving the micrometer headscrew backward. An LVDT monitored the displacement of the pin specimens. A typical force-time trace resulting from such adhesion experiments is seen in Fig. 3. Contact occurs at point $A$. The line A-B represents the region where the load is being applied. The displacement $B X$ corresponds to the normal load. The line $B-C$ represents the region where the contact is maintained at the given load and surfaces of the specimens are stationary. Line $C-D$ represents the region where both the unloading and separation forces are being applied on the adhesion junction. At point $D$ the onset of separation occurs. The displacement or corresponds to the pull-off force. After separation of the pin specimen from the flat, the $p$ in fluctuates back and forth, as represented by the D-E region.

For in situ friction experiments, the flat specimen was brought into contact with the pin specimen by manually moving a micrometer headscrew. Contact was maintained for $30 \mathrm{sec}$; then sliding was initiated by moving the flat specimen in a vertical direction. Friction force was continuously monitored during a friction experiment. The sliding velocity was $3 \mathrm{~mm} / \mathrm{min}$.

RESULTS AND DISCUSSION SiC-to-SiC Contact

An increase in the surface temperature of a ceramic material tends to promote surface chemical reactions. These chemical reactions cause products

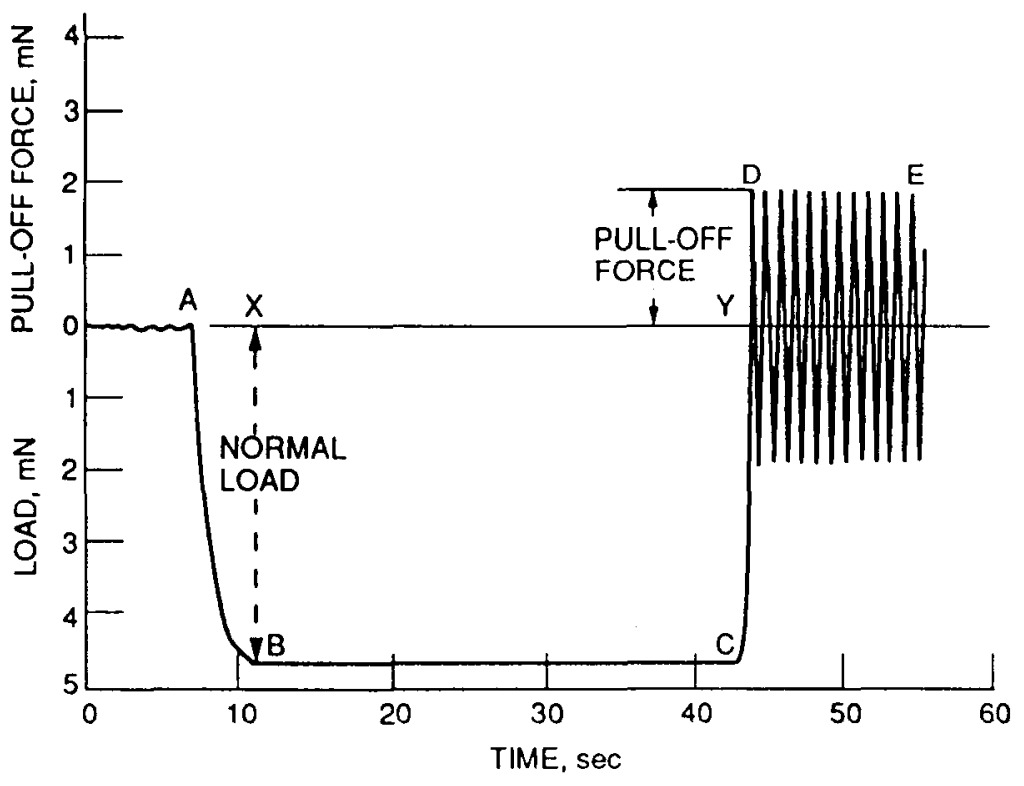

Figure 3. - Typical force-time irace. 
to appear on the surface which can alter adhesion, friction, and wear [il]. For example, when an as-received silicon carbide surface was placed in a vacuum, the principal contaminants (determined by XPS) on the as-received silicon carbide surface were adsorbed carbon and oxygen, silicon oxides, and residual graphite $[11,13]$. When the as-received silicon carbide surface was heated in a vacuum to $400^{\circ} \mathrm{C}$, the adsorbed carbon contaminants disappeared. In addition to nominal silicon carbide, the surface heated at temperatures of $400{ }^{\circ} \mathrm{C}$ and above contained small amounts of graphite and silicon dioxide on the silicon carbide surface. The amount of silicon dioxide present on the silicon carbide surface decreased rapidly with increasing temperature in the range of 600 to $800{ }^{\circ} \mathrm{C}$. At $800^{\circ} \mathrm{C}$ and above, the graphite concentration increased markedly with an increase in temperature, whereas the silicon carbide concentration decreased rapidly in intensity at the silicon carbide surface. The surface of silicon carbide graphitizes.

Figure 4 presents the average pull-off forces for the silicon carbide $(0001)$ surfaces in contact with a sintered polycrystalline silicon carbide pin as a function of temperature in a vacuum. The average pull-off force and the maximum and minimum measured values of pull-off forces were obtained from seven or more measurements. The pull-off force (adhesion) generally remained low at temperatures to $400{ }^{\circ} \mathrm{C}$. The low adhesion can be associated with the presence of the contaminants on the as-received flat specimen surface. The pull-off force increased rapidly at $400^{\circ} \mathrm{C}$. Although the pulloff force decreased slightly at $600^{\circ} \mathrm{C}$, it remained relatively high in the range of 400 to $700{ }^{\circ} \mathrm{C}$. The rapid increase in the adhesion at $400^{\circ} \mathrm{C}$ can be attributed to the absence of adsorbed contaminants such as carbon. The somewhat low values of puli-off force at $600{ }^{\circ} \mathrm{C}$ are probably due to the $\alpha$-quartz to $\beta$-quartz transition of silicon dioxide at about $583^{\circ} \mathrm{C}(856 \mathrm{~K})$

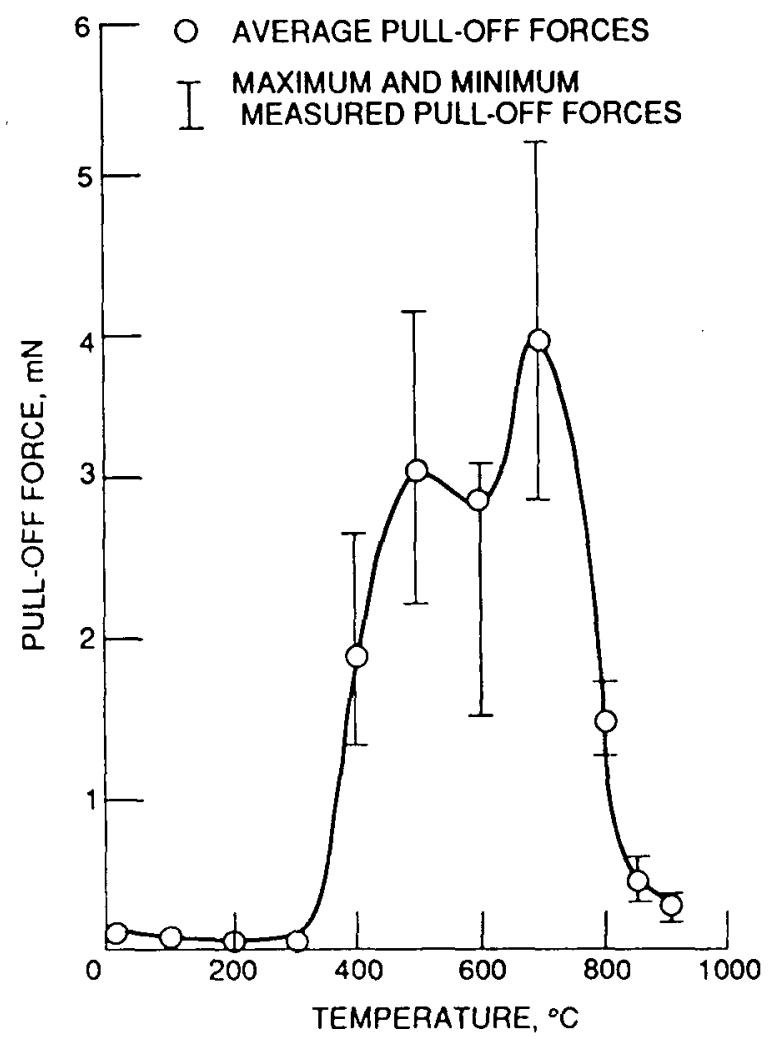

Figure 4. - Pull-off force (adhesion) as function of temperature for silicon carbide (0001) flat surfaces in contact with sintered polycrystalline silicon carbide pins in vacuum. 
[14]. Above $800^{\circ} \mathrm{C}$, the pull-off force decreased rapidly with an increase of temperature. The rapid decrease in pull-off force above $800{ }^{\circ} \mathrm{C}$ correlated with the graphitization of the silicon carbide surface.

Figure 5 presents the coefficients of static and dynamic friction for the silicon carbide $(0001)$ surfaces in contact with sintered polycrystalline silicon carbide pins as a function of temperature in a vacuum. The average coefficient of friction and the maximum and minimum measured values of coefficlents of friction were obtained from five or more measurements. The static and dynamic friction characteristics are the same as those of adhesion presented in Fig. 4. The coefficient of static and dynamic friction generally remained low at temperatures to $400^{\circ} \mathrm{C}$. The low friction is due to the presence of the contaminants on the flat specimen surface, as mentioned earlier. The coefficients of static and dynamic friction increased rapidly at $400^{\circ} \mathrm{C}$, remaining $h i g h$ in the range of 400 to $700{ }^{\circ} \mathrm{C}$. The rapid increase in the static and dynamic friction is related to the absence of adsorbed contaminants such as carbon. The somewhat low values of coefficlent of static and dynamic friction due to the transition of silicon dioxide at about $600^{\circ} \mathrm{C}$ are also seen in $\mathrm{Fig}$. 5(a) and (b). Above $800^{\circ} \mathrm{C}$ the coefficient of static and dynamic friction decreased rapidly with an increase in temperature. Again, the rapid decrease in friction above $800^{\circ} \mathrm{C}$ corresponded to the graphitization of the silicon carbide surface.

\section{Al2 ${ }_{3}$-to-Amorphous Alloy Contact}

Temperature effects (not only above the crystallization temperature but also below $i t$ ) lead to drastic changes in the microstructure and in the surface chemistry of amorphous alloys as characterized by transmission electron microscopy, electron diffraction, and x-ray photoelectron spectroscopy.

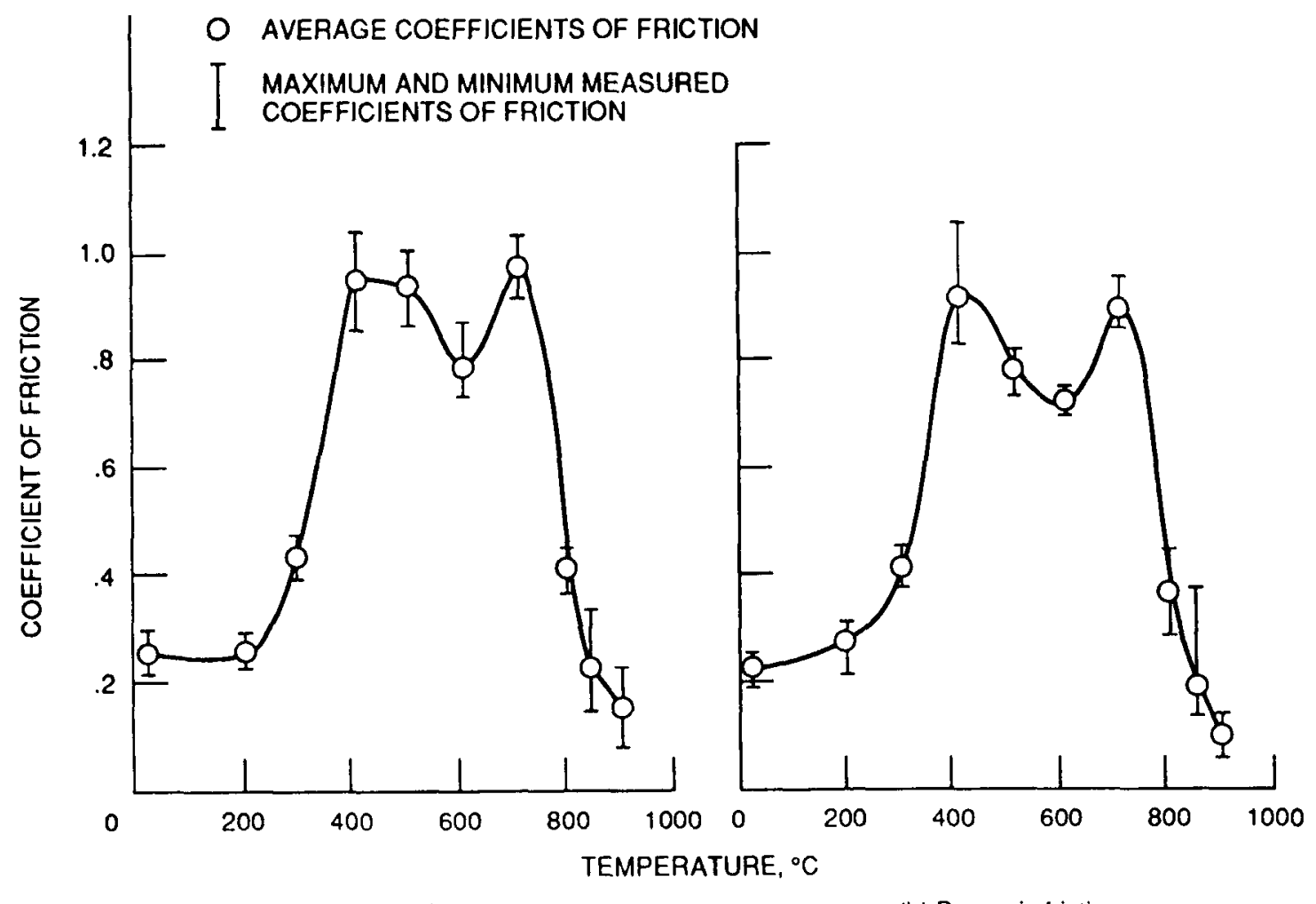

(a) Static friction.

(b) Dynamic friction.

Figure 5. - Coefficients of static and dynamic triction as functions of temperature for silicon carbide $(0001)$ flat surfaces in contact with sintered polycrystalline silicon carbide pins in vacuum. 
These changes are due to segregation and diffusion of constituents, especially of metalloids such as boron and silicon [12]. Table I summarizes the surface conditions of the amorphous alloys analyzed by XPS. Generally, the XPS results indicate that the surfaces of the as-received amorphous alloys consisted of a layer of oxides of alloying elements as well as a simple adsorbed film of oxygen and carbon. The argon ion-sputter-cleaned surface consisted of the alloy and small amounts of oxides and carbides. In addition to nominal element constituents, the surfaces of $67 \mathrm{Fe}-18 \mathrm{Co}-14 \mathrm{~B}-1 \mathrm{Si}$ and $81 \mathrm{Fe}-$ 13.5B-3.5Si-2C alloys heated to $350^{\circ} \mathrm{C}$ contained boric and silicon oxides. and the surfaces of $40 \mathrm{Fe}-38 \mathrm{Ni}-4 \mathrm{Mo}-18 \mathrm{~B}$ alloys contained boric oxides as we 11 as small amounts of carbides that had segregated and migrated from the bulk of the alloys. The surface heated to $750^{\circ} \mathrm{C}$ contained boron nitride that had also migrated from the bulk of the alloys as well as small amounts of oxides.

Thus, in situ examinations of the surface chemistry in the heating stage give valuable information on the behavior of surface segregation and decomposition. The segregation and migration of compounds such as boric oxides and nitrides influence the friction behavior of amorphous alloys.

In situ sliding friction experiments were also conducted with the aluminum oxide pin in contact with amorphous alloys in a vacuum at temperatures up to $750^{\circ} \mathrm{C}$. Friction force traces resulting from such sliding were generally characterized by fluctuating behavior with evidence of stick-slip [15]. The coefficient of friction as a function of the sliding temperature of the alloy specimens is indicated in Fig. 6. The coefficient of friction increased with increasing temperature from room temperature to $350^{\circ} \mathrm{C}$. The increase in friction is due to an increase in the adhesion resulting from migration of boric oxides and silicon oxides to the alloy surface. Generally, the presence of oxygen does strengthen the metal-to-oxide ceramic contacts and increases the friction $[16,17]$.

Above $500^{\circ} \mathrm{C}$ the coefficient of friction decreased drastically. The rapid decrease in friction above $500^{\circ} \mathrm{C}$ correlated well with the migration of boron nitride on the alloy surface, as shown in Table I. It is also interesting to note that in Fig. 6 there is a considerable difference in the friction measured as a result of variations in alloy chemistry.

tABLE I. - SURfACE OF AMORPHOUS aLLOYS

\begin{tabular}{|c|c|c|c|c|}
\hline \multirow{2}{*}{ Alloy composition. } & \multicolumn{4}{|c|}{ Surface } \\
\hline & As received & Argon sputter cleaned & Heated to $350^{\circ} \mathrm{C}$ & Heated to $750^{\circ} \mathrm{C}$ \\
\hline $67 \mathrm{Fe}-18 \mathrm{CO}-14 \mathrm{~B}-151$ & $\begin{array}{l}\text { Oxides of } \mathrm{Fe}, \mathrm{Co} \\
\mathrm{B}, \mathrm{Si} \text {, and } \mathrm{C} \\
\text { Adsorbed } \mathrm{fi} \mathrm{im} \text { of } \\
\text { oxygen and carbon }\end{array}$ & $\begin{array}{l}\text { Alloy } \\
\text { Small amount of } \\
\text { oxldes and carbides }\end{array}$ & $\begin{array}{l}\text { Alloy } \\
\text { Borlc oxides and silicon } \\
\text { cxides migrated from bulk } \\
\text { Small amount of carbides }\end{array}$ & $\begin{array}{l}\text { Alloy } \\
\text { Boron nitride } \\
\text { migrated from bulk } \\
\text { Very small amount } \\
\text { of borlc oxides } \\
\text { and silicon oxides }\end{array}$ \\
\hline $81 F e-13.58-3.55 i-2 C$ & $\begin{array}{l}\text { Oxides of } \mathrm{Fe}, \mathrm{B} \text {, } \\
\text { Si, and } \mathrm{C} \\
\text { Adsorbed film of } \\
\text { oxygen and carbon }\end{array}$ & $\begin{array}{l}\text { Alloy } \\
\text { Small amount of } \\
\text { oxides and carbides }\end{array}$ & $\begin{array}{l}\text { Alloy } \\
\text { Boric oxides and silicon } \\
\text { oxides migrated from bulk } \\
\text { Small amount of carbides }\end{array}$ & $\begin{array}{l}\text { Alloy } \\
\text { Boron nitride } \\
\text { migrated from bulk } \\
\text { Very small amount } \\
\text { of boric oxides } \\
\text { and sillicon oxides }\end{array}$ \\
\hline $40 F e-38 \mathrm{Ni}-4 \mathrm{MO}-18 \mathrm{~B}$ & $\begin{array}{l}\text { Oxides of } F e, B \text {, } \\
\text { MI. Mo, and } B \\
\text { Adsorbed film of } \\
\text { oxygen and carbon }\end{array}$ & $\begin{array}{l}\text { Alloy } \\
\text { Small amount of } \\
\text { oxides and carbides }\end{array}$ & $\begin{array}{l}\text { Alloy } \\
\text { Boric oxides migrated } \\
\text { from bulk } \\
\text { Small amount of carbides }\end{array}$ & $\begin{array}{l}\text { Alloy } \\
\text { Boron nitride } \\
\text { migrated from bulk } \\
\text { Very small anount } \\
\text { of boric oxides }\end{array}$ \\
\hline
\end{tabular}




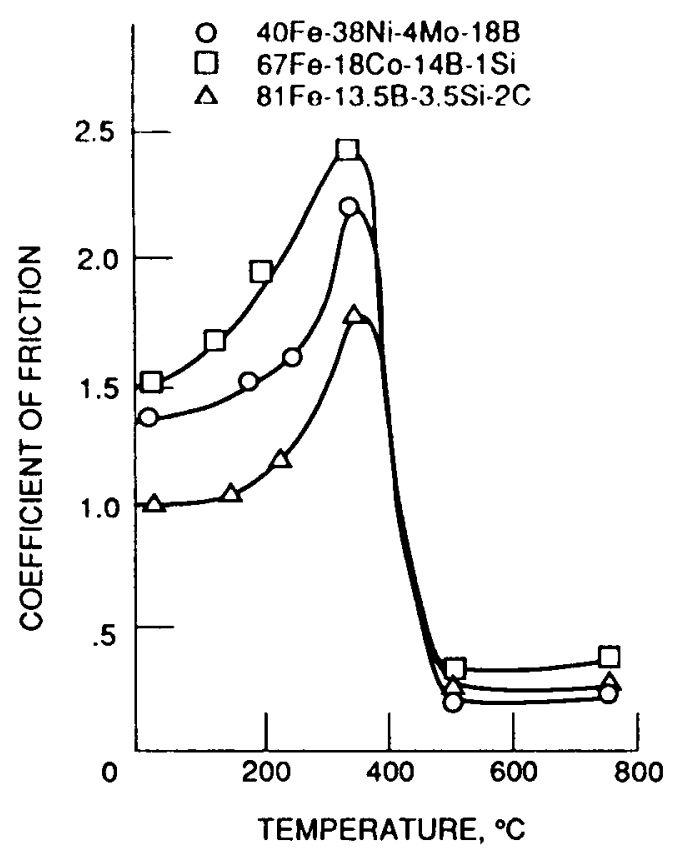

Figure 6. - Coefficient of friction as function of temperature for aluminum oxide pins sliding on amorphous alloys.

\section{CONCLUDING REMARKS}

Based on the design and development of the torsion balance adapted for pull-off force measurements and the fundamental studies of adhesion and friction conducted with silicon carbide in contact with itself and aluminum oxide in contact with amorphous alloys, the following remarks can be made.

Even at elevated temperatures in vacuum, the torsion balance has proven to be valuable in studying the interfacial adhesion properties of materials. This system can make simple and accurate in situ pull-off force measurements without being affected by gravity and buoyancy. Forces as low as $1 \mu \mathrm{N}$ can be measured. The accuracy of measuring pull-off forces does not change with the size and weight of the specimen.

Both pull-off force and friction force measurements are effective in gaining quantitative information on interfacial bond strengths. The behavior of static and dynamic friction is primarily related to that of adhesion (pull-off force).

The characteristics of pull-off force and friction force are strongly dependent on the chemical structure of the ceramic surfaces and that of the materials with which contact is made.

\section{REFERENCES}

1. D. Tabor, in Tribology in Particulate Technology, edited by B.J. Briscoe and M.J. Adams (Adam Hilger-Bristol, 1987), D. 206.

2. D.H. Buckley, Surface Effects in Adhesion, Friction, Wear and Lubrication, (El sevier, New York, 1981).

3. H.E. Hinterman, Wear 100, 381 (1984).

4. S.V. Pepper, J. Vac. Sci. Technol. 20,643 (1982).

5. K.H. Johnson and S.V. Pepper, J. Appl. Phys. 53, 6634 (1982).

6. J. Ferrante, and J.R. Smith, Phys. Rev. B 31,3427 (1985).

7. H. Czichos, J. Phys. D Appl. Phys., 5, $189 \overline{0}$ (1972). 
8. D. Tabor, in New Directions in Lubrication, Materials, Wear and Surface Interactions: Tribology in the $80^{\prime} \mathrm{s}$, edited by W.R. Loomis, (Noyes Publications, Park Ridge, NJ, 1985), p. I (also, in NASA CP-2300).

9. F.W. Sears and M.W. Zemansky, College Physics Part 1-Mechanics, Heat, and Sound, 2nd ed., (Addison-Wesley Press, Cambridge, MA, 1952).

10. K. Miyoshi, C. Maeda and R. Masuo, in Proceedings of the Eleventh Triennial World Congress of the International Federation of Automatic Control (IMEKO), (International Federation of Automatic Control, 1988), p. 263. (NASA TM-100799.)

11. K. Miyoshi and D.H. Buckley, Appl. Surf. Sci. 10, 357 (1982).

12. K. Miyoshi and D.H. Buckley, Wear $110,295(19 \overline{86})$.

13. K. Miyoshi, D.H. Buckley, and M. Srinivasan. Am. Ceram. Soc. Bull. 62, 494 (1983).

14. R.C. Weast, ed., CRC Handbook of Chemistry and Physics, 68th ed., (CRC Press Inc., Boca Raton, FL, 1987).

15. K. Mi yoshi and D.H. Buckley, NASA TP-2006 (1982).

16. S.V. Pepper, J. Appl. Phys. 47, 801 (1976).

17. K. Mi yoshi and D.H. Buckley, Ceram. Eng. Sci. Proc. 4(7-8), 674 (1983). 


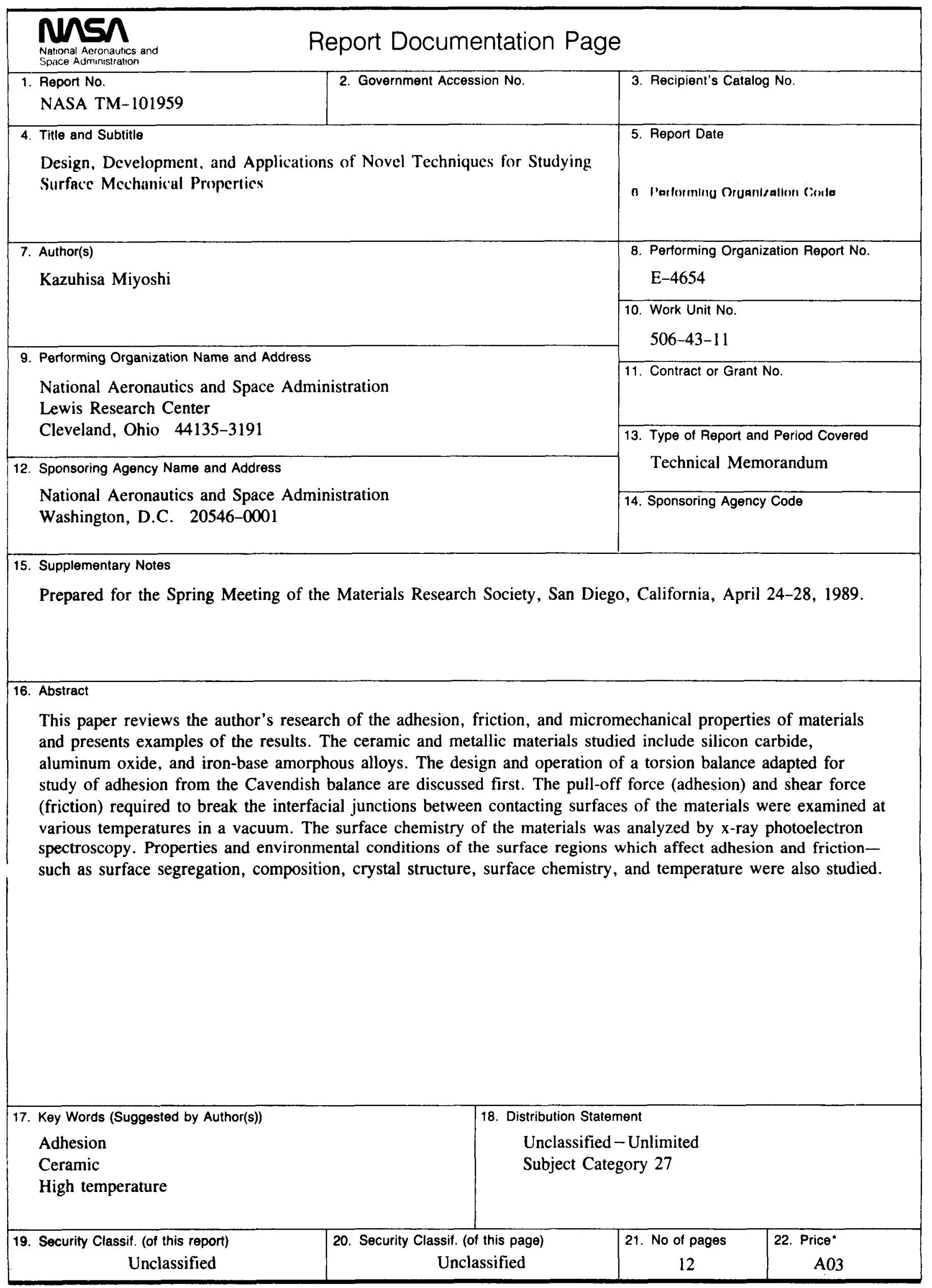

